\title{
Condições de trabalho docente: novas tessituras das políticas de avaliação para a qualidade
}

Conditions of teaching: new weavings of the assessment policy for quality

Elton Luiz Nardi*

Universidade do Oeste de Santa Catarina

Marilda Pasqual Schneider**

Universidade do Oeste de Santa Catarina

Resumo $\mathrm{O}$ artigo tem por objetivo analisar ações que implicam o trabalho docente, nomeadamente as que se referem às condições objetivas de trabalho e de emprego, tendo em conta novas tessituras das políticas de avaliação para a qualidade da educação básica implicadas no Ideb. Examina ações informadas por gestores escolares e docentes do ensino fundamental, no tocante à melhoria da qualidade educacional. Assinala que, embora muitas ações informadas impliquem as condições de trabalho docente, a maioria delas focaliza condiccões de ordem material e, foi traçada tendo o Ideb como fator mobilizador. Conclui que: o protagonismo ao qual a escola é chamada a exercer concentra-se na produção de resultados visando, metas nacionais que têm asseverado as já difíceis condições de trabalho dos docentes.

PALAVRAS-CHAVE: Políticas de avaliação, Ideb, Condições de trabalho docente.

Abstract The article aims to analyze actions involving teaching, particularly those relating to the objective conditions of work and of employment, taking into account new weavings of policy evaluation for the quality of basic education involved in Ideb. It examines actions informed by school administrators and elementary school teachers, aiming at improving educational quality. Points out that, although many informed actions involve teachers' working conditions, the majority of them focuses on the material conditions and it was drawn taking Ideb as a mobilizing factor. It was concluded that the role the school is called to exercise focuses on producing results aiming national goals that have already asserted the difficult working conditions of teachers.

KEYWORDS: Assessment policies, Ideb, Teacher working conditions. 


\section{Introdução}

Embora o Índice de Desenvolvimento da Educação (Ideb) seja figura recente na educação brasileira, já não é mais uma novidade para as escolas de educação básica. Sua massiva divulgação pelos órgãos governamentais e pela mídia, bem como a exigência dos governos na observância às metas traçadas, repercutem na gestão das escolas e nas condições do trabalho docente.

A criação do índice inscreve-se no quadro das políticas de avaliação da educação básica, encampadas especialmente a partir da década de 1990, sob a lógica do fortalecimento do papel regulador do Estado brasileiro sobre o setor educacional, e que tomam, por base, a necessidade de melhoria da qualidade da educação básica no país. Como consequência, professores e gestores escolares são instados a atuar de modo a assegurar o alcance das metas bianuais do Ideb, reforçando o que se tem chamado de simplificação a padrões educacionais desejáveis de problemas educativos de maior complexidade (SOUSA; OLIVEIRA, 2010).

Desde 2007, ano da criação e da divulgação de resultados do índice, muitos estudos tem sido realizados, especialmente na área da Educação, tendo em conta esse novo ingrediente que, atualmente, atravessa os temas da avaliação e da qualidade da educação, estes são frequentemente relacionados à ocorrência de uma legitimação da qualidade pelo horizonte restrito da competitividade (FONSECA, 2009). Os sentidos e as repercussões do Ideb, na escola pública de educação básica, são, em grande medida, foco das questões levantadas nesses estudos. ${ }^{1}$

Atentos a essa realidade, e, tendo em vista as circunstâncias a que estão submetidas as escolas no contexto das prioridades informadas por metas do Ideb, o presente trabalho tem por objetivo analisar ações que implicam o trabalho docente, previstas ou implementadas por escolas municipais, nomeadamente as que se referem às condições objetivas de trabalho e de emprego dos seus professores.

O trabalho toma, por base, os resultados parciais de uma investigação ${ }^{2}$ que busca avaliar a potencialidade e o alcance das estratégias e ações deflagradas por redes e escolas públicas, visando à melhoria da qualidade educacional, cujo campo empírico compreende 18 municípios e 18 escolas municipais de ensino fundamental de Santa Catarina, escolhidos segundo critérios de porte populacional e de localização na mesorregião. Em relação ao porte populacional, o critério considerou: $50 \%$ de municípios com até 10.000 habitantes; $30 \%$ de municípios com mais de 10.000 até 30.000 habitantes; e, 20\% de municípios com mais de 30.000 habitantes. Já, em relação ao critério de localização, garantiu-se a representação de municípios de todas as microrregiões correspondentes à área da mesorregião pesquisada. Além disso, dentre o conjunto de municípios amostrados, dez são considerados prioritários pelo MEC para o repasse de recursos financeiros e assistência técnica. No âmbito de cada município, a escolha da escola recaiu naquela com o menor Ideb registrado em 2007 e que, preferencialmente, oferecesse o ensino fundamental completo.

Considerando o campo empírico determinado, examina dados colhidos com a aplicação de questionários aos gestores escolares e entrevistas a estes e a professores do ensino fundamental das escolas investigadas. Por meio dos questionários, aplicados numa primeira etapa do processo de pesquisa, levantaram-se as ações e es- 
tratégias traçadas pela escola para o período compreendido entre os anos de 2010 e 2012, visando à melhoria da qualidade da educação. Já as entrevistas, realizadas em etapa posterior, tiveram por propósito o levantamento de opiniões de gestores e professores acerca da efetividade das ações e estratégias traçadas. No presente estudo, os dados e informações colhidos foram submetidos à análise quali-quantitativa, considerando-se dois campos específicos: o das condições de emprego e o das condições objetivas de realização do trabalho docente.

Orientados pelo objetivo traçado, iniciamos com a apresentação de algumas notas sobre o Ideb, reconhecendo-o como peça das políticas de avaliação em larga escala encampadas no Brasil a partir dos anos de 1990, com a intenção declarada de regular a qualidade da educação básica no país. Na sequência, apresentamos e analisamos as ações informadas por gestores escolares como destinadas à melhoria da qualidade educacional, mais especificamente as que têm implicações diretas no trabalho docente, nomeadamente as que incidem nas condições objetivas de trabalho e nas de emprego ou carreira.

Nessa direção, são realçados os aspectos mais frequentemente enfocados nas ações previstas ou implementadas, analisando-se possíveis decorrências das condições efetivas de trabalho do professor. Nesta etapa do trabalho, a análise também vem parametrizada pelas entrevistas realizadas com docentes de $4^{\mathrm{a}}$ série do ensino fundamental e das disciplinas de Língua Portuguesa e Matemática das $8^{a}$ séries, bem como com gestores das 18 escolas pesquisadas.

\section{Políticas de avaliação em larga escala: situando o Ideb}

Sob a égide de uma política de regulação do fluxo escolar, foi criado, no ano de 1990, o Sistema de Avaliação da Educação Básica (Saeb), com exames externos e de caráter amostral. Segundo destacam Bonamino e Franco (1999), o Saeb foi inspirado no Programme for International Student Assessment (PISA), um exame de natureza internacional, promovido pela Organização para Cooperação e Desenvolvimento Econômico (OCDE), com raízes em demandas do Banco Mundial.

Com a utilização da Teoria da Resposta ao Item (TRI), adotada a partir de 1995, o exame do Saeb permitiu comparações no decorrer dos anos, favorecendo a construção de um panorama do desempenho dos estudantes de $4^{\mathrm{a}}$ e $8^{\mathrm{a}}$ séries (atualmente $5^{\mathrm{a}}$ e $9^{\mathrm{a}}$ séries) do ensino fundamental, e da $3^{\mathrm{a}}$ série do ensino médio, em Língua Portuguesa e Matemática, em nível nacional e estadual, nas redes rurais e urbanas, públicas e privadas.

No ano de 2005, o Saeb sofreu adequações quanto à sua natureza e abrangência. Em atenção à Portaria Ministerial no 931/2005, o exame passou a ser subdivido em Anresc (Avaliação Nacional do Rendimento Escolar), conhecida por Prova Brasil, e Aneb (Avaliação Nacional da Educação Básica), designada pelo mesmo nome que agora abriga o sistema nacional de avaliação (BRASIL, 2005).

A Prova Brasil possui a mesma metodologia de realização do Saeb, assemelhando-se a ele em vários aspectos. É bianual e avalia as mesmas áreas de conhecimento, porém sua abrangência é censitária, ou seja, permite análise mais detalhada dos sistemas educacionais exatamente por oferecer dados por escola e por município. 
Essa avaliação passou a aferir o desempenho dos estudantes de $5^{\mathrm{a}}$ e $9^{\mathrm{a}}$ séries do ensino fundamental da rede pública urbana.

Juntamente com o Saeb, a Prova Brasil representa hoje uma das forças mais expressivas da cultura da avaliação, em larga escala no Brasil, em vista do lugar que ocupa na delimitação de indicadores de qualidade da educação básica. Isso porque os resultados obtidos pelos estudantes nesses dois instrumentos alimentam o Ideb.

Aportado no Plano de Desenvolvimento da Educação (PDE), o Ideb foi criado em 2007 para aferir resultados educacionais dos estados, municípios, redes de ensino e escolas de educação básica do país. A despeito do ano de sua criação (2007), a série histórica do Ideb data de 2005 , donde, a partir de então, segue com avaliações bienais.

O índice resulta do produto entre o desempenho dos alunos na Prova Brasil/Saeb (N), compreendendo a média da proficiência em Língua Portuguesa e Matemática expressa por um indicador entre 0 e 10, e o rendimento escolar $(\mathrm{P})$, baseado na taxa de aprovação dos alunos na etapa de ensino, taxa esta aferida por meio do Censo Escolar e expressa por valores entre 0 e 1 . $\mathrm{O}$ indicador de rendimento é o inverso do tempo médio em anos que os alunos levam para completar uma série, ${ }^{4}$ o que pode ser traduzido na seguinte equação: Ideb $=\mathrm{N} x(1 / \mathrm{T})$.

Por isso, se o fluxo escolar for regular, ou seja, se o tempo médio de conclusão de cada série de uma etapa for de um ano, o Ideb da escola e dos municípios equivale ao indicador de desempenho obtido na Prova Brasil/Saeb. ${ }^{5}$ Do contrário, quanto maior a taxa de reprovação e de abandono registrados na etapa, maior será o tempo médio (T) de conclusão de uma série, o que claramente penaliza o resultado obtido na proficiência. Para Fernandes (2007, p. 8), além de aplicável às escolas, o índice é "explícito em relação à 'taxa de troca' entre probabilidade de aprovação e proficiência dos estudantes."

O Ideb representa uma iniciativa pioneira, até então no Brasil, de se acompanhar a qualidade da educação básica a partir de dois indicadores - rendimento escolar e desempenho -, possibilitando, com isso, a incorporação de objetivos de accountability na educação básica, com responsabilização dos atores educacionais pelos resultados de suas unidades.

O reforço a essa incorporação deu-se pela adoção de metas por escola, rede de ensino e município, com as quais os governos locais comprometeram-se por meio da adesão formal ao Plano de Metas "Compromisso Todos Pela Educação". Por tudo isso, o Ideb tornou-se o índice de maior impacto na qualidade da educação básica brasileira.

Tendo-lhe sido atribuído o posto de tradutor oficial da qualidade da educação básica, na prática, é a partir do Ideb que gestores e professores são chamados a propor medidas que possibilitem o alcance de melhores resultados educacionais. Esses resultados, por sua vez, encontram-se perspectivados no horizonte do sistema de metas pactuado entre o MEC e as unidades subnacionais.

Sob o prisma da função que espera desempenhar o índice, ações e estratégias operadas pelas escolas de educação básica não só são esperadas, como devem 
focalizar condições que sejam potencialmente conducentes à melhoria dos indicadores submetidos à aferição.

Ainda que essa dinâmica possa ser vista como uma forma ostensiva de garantir qualidade, um dos seus maiores efeitos tem sido a considerável pressão sobre os docentes para que ensinem, visando a que seus alunos logrem êxito nos testes nacionais, de modo a alcançar as metas bianuais traçadas para cada escola. Somada à multiplicidade de atribuições a que o professor tem sido levado a assumir, essa pressão tem realçado as difíceis condições de trabalho de que dispõe para exercer o seu ofício e a necessidade de fortalecimento do debate sobre o tema da carreira docente, este com tom de prioridade.

\section{Reformas educacionais e reestruturação do trabalho docente}

O trabalho docente é uma categoria que abarca os sujeitos que atuam no processo educativo das escolas e de outras instituições de educação, considerada a diversidade de cargos, funções, tarefas, especialidades e responsabilidades desses sujeitos, e as atividades laborais por eles realizadas (OLIVEIRA, 2010). Por extrapolar a regência de classe, o trabalho docente pode ser definido como todo ato de realização no âmbito do processo educativo.

De acordo com Birgin (2002, p. 98), o trabalho docente "constrói-se precisamente nas formas cotidianas da micropolítica institucional, no entrelaçamento das condições materiais e nas relações sociais". Portanto, ele se estabelece a partir de processos de negociação inscritos em uma rede de relações internas e externas que se entrecruzam no espaço escolar. Analisar o trabalho docente a partir dessa perspectiva implica considerá-lo como um espaço e uma forma de regulação social, com lógicas e contradições inerentes à natureza desse trabalho, produzidas na relação dialética entre determinações estruturais sociais amplas e específicas.

No caso das políticas educacionais empreendidas nas últimas décadas, um evidente reforço da correlação entre educação, desenvolvimento e trabalho vem colocando o professor como peça-chave e protagonista central do processo de mudanças e das possibilidades de reforma do sistema educacional (CASTRO, 2005). Conforme assinala Oliveira (2004), ao referir o movimento de reforma iniciado nos países latino -americanos, na década de 1990, uma nova regulação das políticas educacionais trouxe consequências à organização e gestão da escola. Uma delas diz respeito, justamente, à reestruturação do trabalho docente, implicando alterações na natureza e definição das dimensões desse trabalho e nos enfoques teórico-metodológicos acerca da profissionalização docente.

Por serem os que assumem mais expressivamente o ato educativo, seja em quantidade, seja em envolvimento, os professores são mais frequentemente lembrados quando se mobiliza o termo trabalho docente. Ademais, são a eles que as políticas educacionais creditam o encargo de principais responsáveis pelo processo educativo. No entanto, ao aumento das atribuições ao qual é submetido não corresponde, em igual medida, maior valorização profissional. 
No atual contexto brasileiro, em decorrência das alterações provenientes do processo de reorganização escolar e das recentes regulações sociais, o professor vem sendo chamado a assumir novas incumbências, as quais se somam às atividades reconhecidamente inerentes ao seu trabalho.

Como parte das atividades inerentes ao seu trabalho, os professores desenvolvem tarefas como: participação em reuniões escolares; planejamento das aulas; elaboração e ou seleção de materiais pedagógicos; correção de trabalhos e atividades; organização de atividades externas à escola, tais como excursões e festas escolares; atendimento a pais e responsáveis; e participação em cursos de formação e aperfeiçoamento.

A partir das recentes regulamentações resultantes das reformas educacionais operadas no país, muitas delas associadas às mudanças nos modos de produção, $\mathrm{o}$ professor é chamado a comprometer-se, ainda, com a gestão da escola, a organização do projeto político-pedagógico e outros projetos interdisciplinares, o trabalho com a família e a comunidade, entre outras (DUARTE, 2011). Essas são demandas que extrapolam o trabalho inerente às atividades de ensino, e passam a constituir um espectro cumulativo de atividades que amplia, consideravelmente, suas funções docentes tradicionais.

Mas, que condições concretas concorrem para a realização do trabalho do professor no contexto aqui referido? Essa é uma questão que, ao certo, não conduz a uma resposta padrão, dado que as condições de trabalho situam-se sempre em um contexto histórico-social e econômico no qual elas também são engendradas.

\section{Ações previstas ou implementadas pelas escolas: implicações nas condições de trabalho}

Do levantamento das ações previstas ou implementadas pelas escolas investigadas, e considerando estudos de Oliveira e Assunção (2010), a análise sobre as que incidem nas condições de trabalho docente tomou por base dois campos: o das condições de emprego e o das condições objetivas de realização do processo de trabalho.

Seguindo Duarte (2011), enquanto as condições de emprego associam-se mais diretamente à carreira docente (salário, jornada de trabalho, contratos, tempos remunerados para o trabalho coletivo, formação continuada e outros), as condições objetivas de realização do processo de trabalho têm a ver com as condições materiais, portanto, com o ambiente físico-organizacional, no qual se desenvolve o trabalho docente (espaço físico, equipamentos, material de consumo e material didático, entre outros, que oferecem subsídios ao trabalho).

Nos dados coligidos, foram identificados seis tipos distintos de ações, cuja especificidade permite que sejam abarcadas nos dois campos de condições de trabalho aqui referidos. No total, foram identificadas 51 ações previstas ou implementadas pelas escolas e que, portanto, constituem o corpus submetido à análise. Destas, 36 delas $(64,7 \%)$ são afetas às condições objetivas de trabalho e 15 outras $(35,3 \%)$ relacionadas às condições de emprego. $\mathrm{O}$ enfoque da maioria das ações mapeadas vem justificado na necessidade de enfrentamento de fatores intervenientes no processo ensino-aprendizagem, sobre os quais os docentes são chamados a atuar. 
Atentos à recorrência de ações que implicam as condições de trabalho docente, indicadas pelas escolas por meio de seus gestores, os achados da pesquisa nos levaram à demarcação das escolas em três conjuntos.

Em um primeiro conjunto, representado por $50 \%$ das escolas amostradas, a maior parte do total das ações informadas implica mais diretamente as condições de trabalho docente. Nesse primeiro conjunto, de 36 ações identificadas, 22 delas $(61,1 \%)$ dizem respeito às condições objetivas de realização do processo de trabalho. Conforme ilustra o Gráfico 1, entre essas 22 ações, sobressaem as de (a) aquisição de materiais e equipamentos e de (b) melhoria e ampliação das instalações físicas da escola.

Gráfico 1 - Ações incidentes nas condições objetivas de realização do processo de trabalho, previstas ou implementadas pelo primeiro conjunto de escolas (50\% das instituições amostradas)

Total de ações que implicam condições objetivas de trabalho

a) Aquisição de materiais/equipamentos b) Melhoria/ampliação das instalações físicas

c) Outras

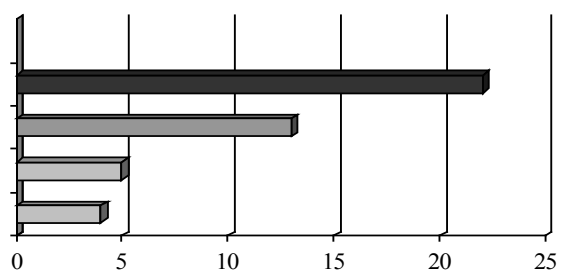

Fonte: organizado pelos autores com base na pesquisa do Obeduc.

Já, em um segundo conjunto, composto por sete escolas pesquisadas (39\% do total), as ações mencionadas pelos gestores possuem menor focalização nas condições de trabalho docente. Nesse conjunto foram identificadas somente 15 ações e, conforme indica o Gráfico 2, 11 delas $(73,3 \%)$ incidem mais diretamente nas condições objetivas de realização do processo de trabalho. As ações abarcadas por essa categoria, nesse segundo conjunto, também se concentram na (a) aquisição de materiais e equipamentos e na (b) melhoria e ampliação de instalações físicas.

Gráfico 2 - Ações incidentes nas condições objetivas de realização do processo de trabalho, previstas ou implementadas pelo segundo conjunto de escolas (39\% das instituições amostradas)

Total de ações que implicam condições objetivas de trabalho

a) Aquisição de materiais/equipamento

b) Melhoria/ampliação das instalações físicas

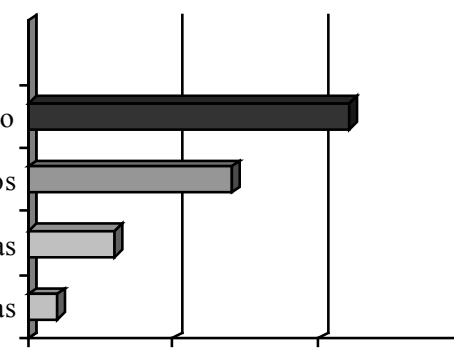

Fonte: organizado pelos autores com base na pesquisa do Obeduc. 
Um terceiro conjunto, representado por duas das escolas pesquisadas (11\%), compreende estabelecimentos em que as ações informadas não têm incidência nas condições aqui analisadas ou, de outra forma, não houve o registro de informações.

Evidenciada a maior extensão do número de ações afetas às condições objetivas do ambiente físico-organizacional, no qual se desenvolve o trabalho docente, tanto por parte das escolas do primeiro conjunto, como das que constituem o segundo conjunto, cabe realçar que as ações que incidem mais diretamente nas condições de emprego ou carreira docente - o segundo campo de análise - correspondem a 38,9\% do total de iniciativas traçadas pelas escolas do primeiro conjunto (14 ações) e somente a $26,7 \%$ das traçadas pelas do segundo (4 ações).

Como se pode verificar, no Gráfico 3, dentre as ações que incidem nas condições de emprego ou carreira, a preponderância das voltadas à formação continuada de professores $(57,1 \%$ no primeiro e $50 \%$ no segundo conjunto constitui traço comum nos dois conjuntos de escolas. Já, a ação versando sobre plano de carreira foi referida apenas duas vezes, por uma escola do primeiro e uma do segundo conjunto, situação indicativa do caráter periférico que, por alguma razão, ações dessa natureza assumem no contexto do planejamento das escolas.

Gráfico 3 - Ações incidentes nas condições de emprego ou carreira, previstas ou implementadas por escolas do primeiro conjunto ( $50 \%$ das instituições amostradas) e por escolas do segundo conjunto (39\% das instituições amostradas)

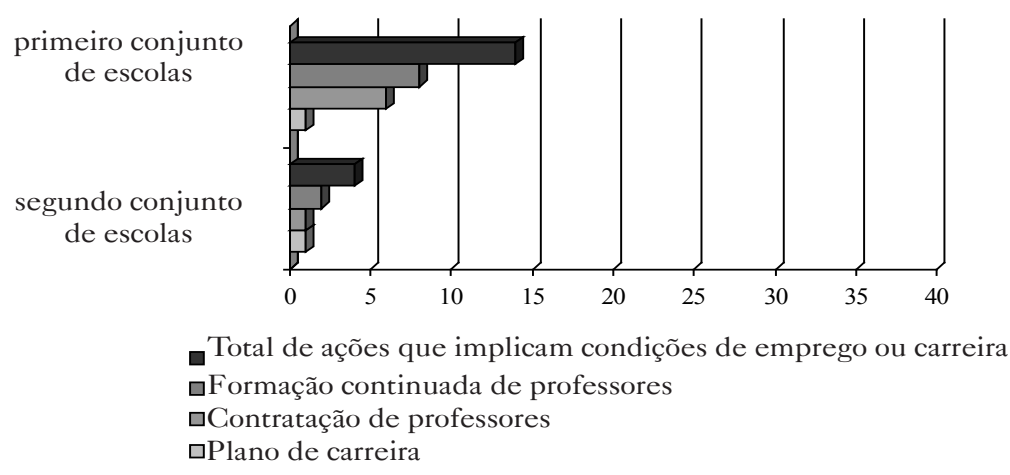

Fonte: organizado pelos autores com base na pesquisa do Obeduc.

A constatação de uma menor presença de ações voltadas às condições de emprego ou carreira e, sobre estas, a concentração em apenas duas frentes (formação continuada e contratação de novos professores), nos leva ao traçado de três hipóteses. A primeira delas considera a pouca expressividade de ações relacionadas à carreira docente como decorrente de uma visão de gestores de que esse assunto diz respeito às políticas educacionais, aos gestores públicos. A escola pública, por não ter autonomia de atuar sobre, nada poderia fazer para alterar um quadro que talvez requeresse mudanças. 
Tão preocupante quanto a primeira, a segunda hipótese diz respeito ao fato de os gestores não considerarem as questões da carreira docente como potencialmente relacionadas às condições para a melhoria da qualidade educacional, o que nos remete às mudanças nas relações de trabalho a que se refere Oliveira (2004), nomeadamente ao fenômeno da precarização dessas relações. Esse fenômeno decorre, especialmente, das novas formas e padrões de uso e remuneração da força de trabalho, o que instiga a flexibilização de contratos de trabalho.

O aumento dos contratos temporários nas redes públicas de ensino, chegando, em alguns estados, a número correspondente ao de trabalhadores efetivos, o arrocho salarial, o respeito a um piso salarial nacional, a inadequação ou mesmo ausência, em alguns casos, de planos de cargos e salários, a perda de garantias trabalhistas e previdenciárias oriunda dos processos de reforma do Aparelho de Estado têm tornado cada vez mais agudo o quadro de instabilidade e precariedade do emprego no magistério público. (OLIVEIRA, 2004, p. 1140)

A terceira hipótese levantada é de que ações relacionadas à carreira docente não teriam merecido referência maior dos gestores das escolas por se tratar de questão resolvida no contexto das escolas públicas investigadas, e, portanto, ações nessa direção já não representariam uma necessidade. Sobre a possibilidade de confirmação dessa hipótese, no entanto, recaem fortes ressalvas visto que, ao menos no tocante à carreira inicial dos docentes, persiste um problema estrutural em âmbito nacional, demarcado pela não observância de muitos estados e municípios ao piso salarial dos profissionais do magistério, aprovado pela Lei no 11.738/2008.

De modo geral, a incidência de ações que afetam às condições de trabalho docente, no quadro da maioria das escolas investigadas, informa que, para os gestores, as questões relacionadas à melhoria da qualidade educacional estão diretamente associadas ao trabalho que o professor realiza com os alunos e que este, por sua vez, remete preponderantemente às condições materiais para a sua efetivação. Por fim, ainda com relação ao quadro de ações informado pelas escolas do primeiro conjunto, que traçou o maior número de iniciativas atinentes às condições de trabalho, e do segundo conjunto, com menor concentração de ações voltadas a essas condições, buscamos sistematizar, em um segundo momento da pesquisa, as leituras que fazem os docentes e gestores entrevistados acerca dessas ações. Que créditos atribuem às ações encampadas por suas escolas? Que expectativas nutrem em relação a essas ações?

Acerca do quadro geral de ações informadas, dentre as quais figuram as analisadas nesse trabalho, os gestores escolares, os professores de $4^{\mathrm{a}}$ série do ensino fundamental e os de Língua Portuguesa e Matemática da $8^{a}$ série do ensino fundamental, em sua extensiva maioria, consideram as ações previstas e ou desenvolvidas pela escola apropriadas ao enfrentamento dos desafios postos.

Atentos aos depoimentos relacionados àquelas ações identificadas como incidentes nas condições de trabalho, o exame realizado permitiu constatar que a leitura dos sujeitos vem parametrizada majoritariamente por ações relacionadas às condições objetivas de trabalho, justamente as que representam a maior frente nas escolas pesquisadas, com ênfase no trabalho que o professor realiza com os alunos. Os depoimentos ilustram bem a aposta nessas ações: "Conseguimos fazer com que as aulas sejam mais 
dinâmicas com os materiais didáticos e o laboratório de informática." (Professor de $4^{a}$ série). "Eu acredito que melhorou [...] quanto aos recursos tecnológicos também, porque mandaram à escola uns aparelhos bons e aí conseguimos trabalhar de uma maneira diferente [...]" (Professor de Língua Portuguesa de 8a série). "A estrutura ampliada deu mais comodidade e possibilidade, basta que haja o comprometimento do grupo $[\ldots . . .]^{\prime}$ (Professor de $4^{\mathrm{a}}$ série).

Por outro lado, há entre os sujeitos entrevistados alguns que, embora reafirmem a importância dessas ações, manifestam reservas quanto à efetividade de várias delas, posto julgarem existir desafios à melhoria da qualidade da educação que diversas ações parecem não dar conta de atender satisfatoriamente.

Nesse caso, ainda com ênfase no trabalho que o professor realiza com os alunos, as reservas recaem, principalmente, sobre ações relacionadas às condições de emprego e carreira, nomeadamente à formação continuada, conforme ilustram os seguintes depoimentos:

"Falta formação continuada que contribua para a prática pedagógica." (Professor de 4a série). "Na verdade nós não temos formação mensal [...] O que nós temos hoje é uma busca individualizada de formação, [...] eu pelo menos busco participar de todos os [curso] que me tenham sido facilitados pela liberação da escola ou que tenham sido próximos [...].” (Professor de Matemática de 8a série)."A formação continuada só é efetiva quando obrigatória. Há repetição, sempre se fala a mesma coisa. Questões fora da realidade da sala de aula." (Gestor escolar). "Os cursos de formação são repetitivos, pobres e abstratos.” (Professor de $4^{a}$ série).

Importa considerar, ainda, que a extensiva maioria dos depoentes posicionou-se favoravelmente à existência de relação entre as ações previstas e a busca por melhores resultados no Ideb, embora uma minoria tenha manifestado descrença sobre um impacto positivo das ações nesses resultados. $\mathrm{Na}$ massiva maioria dos casos, os sujeitos entrevistados imputam maior confiança ao trabalho coletivo como potencializador da melhoria da qualidade da educação, uma questão merecedora de análises mais apuradas, mas que fogem ao objetivo deste trabalho.

\section{Considerações finais}

Os resultados do estudo, realizado no âmbito da investigação descrita, dão indicativos de que o protagonismo ao qual a escola é chamada a exercer a partir da criação do Ideb assenta-se, sobremaneira, na produção de resultados com vistas ao alcance das metas nacionais que informam, oficialmente, a qualidade educacional. Afora isso, o quadro explorado sugere existir questões preocupantes que atravessam as condições concretas de trabalho do professor, justamente a quem vem sendo imputada importante carga de responsabilidade na produção desses resultados.

No caso das ações previstas ou implementadas pelas escolas investigadas, com incidência nas condições de trabalho dos professores, a preponderância nas condições de ordem material é, a nosso ver, indicativa de uma concentração de esforços, pelas escolas, na geração de condições para o enfrentamento de fatores intervenientes nos processos de ensino e aprendizagem, sobre os quais os docentes são chamados a 
atuar. Reforça-se, com isso, a tese de que é, destacadamente com o objetivo do alcance de melhores resultados no trabalho com o aluno, que as condições de trabalho do professor tendem a ser justificadas no contexto das atuais políticas de avaliação para a qualidade.

O que informam os dados levantados constitui uma pequena amostra de uma visão generalizada em muitos discursos: a de que o professor é o grande responsável pelas condições de melhoria da qualidade educacional. Em que pese a responsabilidade atribuída a ele pela aprendizagem dos seus alunos, ampliam-se condicionamentos e pressões para o alcance das metas informadas pelo Ideb, delineadas para a escola e para o sistema do qual faz parte o professor.

O desequilíbrio entre ações voltadas às condições de emprego e as que implicam condições objetivas de trabalho reforça, a nosso ver, as já conhecidas críticas tecidas país afora sobre o descompasso entre a gama de responsabilidades a qual o professor tem sido levado a assumir e as condições de trabalho de que efetivamente dispõe. As novas exigências e atribuições que recaem sobre ele, especialmente a partir da implementação de avaliações em larga escala como instrumento de regulação e controle da qualidade educacional, suplantam, muitas vezes, a sua formação e suas condições pessoais, instaurando um sentimento de desprofissionalização e de desqualificação do seu trabalho (OLIVEIRA, 2004).

O cenário aqui descrito instiga-nos a repensar criticamente as condições de trabalho docente, pondo em evidência as contradições presentes nas políticas que atribuem ao professor o papel de artífice das transformações objetivadas pelas reformas educacionais em curso e a necessidade de uma vontade política que possibilite tornar as questões atinentes à carreira docente uma prioridade no debate nacional. Essa é, ao nosso ver, uma via tanto possível como necessária.

\section{Referências}

ALVES, M. T. G.; SOARES, J. F. Contexto escolar e indicadores educacionais: condições desiguais para a efetivação de uma política de avaliação educacional. Educação e Pesquisa, São Paulo, v. 39 n. 1, p. 177-194, jan./mar., 2013.

BIRGIN, A. Novas regulações do trabalho docente: o caso das reforma argentina. Cadernos de Pesquisa, São Paulo, n. 111. p. 95-113, dez. 2002.

BONAMINO, A.; FRANCO, C. Avaliação e política educacional: o processo de institucionalização do SAEB. Cadernos de Pesquisa, São Paulo, n. 108, p. 101-132, nov. 1999.

BRASIL. Portaria n. 931, de 21 de março de 2005. Institui o Sistema de Avaliação da Educação Básica - SAEB. Diário Oficial [da] República Federativa do Brasil, Brasília, DF, 22 mar. 2005, Seção 1, p. 17.

CASTRO, A. M. D. A. Mudanças tecnológicas e suas implicações na política de formação do professor. Ensaio: Avaliação e Políticas Públicas em Educação, Rio de Janeiro, v.13, n. 49, p. 469-486, out./dez. 2005.

DUARTE, A. Políticas educacionais e o trabalho docente na atualidade: tendências e contradições. In: OLIVEIRA, D. A.; DUARTE, A. (Org.). Políticas públicas e educação: regulação e conhecimento. Belo Horizonte: Fino Traço, 2011. p. 161-182.

FERNANDES, R. Índice de desenvolvimento da educação básica (Ideb). Brasília, DF: Inep, 2007. 
FONSECA, M. Políticas públicas para a qualidade da educação brasileira: entre o utilitarismo econômico e a responsabilidade social. Cadernos Cedes, Campinas, v. 29, n. 78, p. 153-177, maio/ago.2009.

FREITAS, L. C. Eliminação adiada: o ocaso das classes populares no interior da escola e a ocultação da (má) qualidade do ensino. Educação \& Sociedade, Campinas, v. 28, n. 100, esp. p. $965-987$, out. 2007.

NARDI, E. L.; SCHNEIDER, M. P. Qualidade na educação básica: entre significações, políticas e indicadores. Educação em Questão, Natal, v. 42, n. 28, p. 227-250, jan./abr. 2012.

OLIVEIRA, D. A. A reestruturação do trabalho docente: precarização e flexibilização. Educação \& Sociedade, Campinas, v. 25, n. 89, p. 1127-1144, set./dez. 2004.

; ASSUNÇÃO, A. A. Condições de trabalho docente. In: OLIVEIRA, D. A., DUARTE, A. M. C.; VIEIRA, L. M. F. Dicionário: trabalho, profissão e condição docente. Belo Horizonte: UFMG/Faculdade de Educação, 2010. CDROM

. Trabalho docente. In: OLIVEIRA, D. A., DUARTE, A. M. C.; VIEIRA, L. M. F. Dicionário: trabalho, profissão e condição docente. Belo Horizonte: UFMG/Faculdade de Educação, 2010. CDROM.

SOUSA, S. Z.; OLIVEIRA, R. P. Sistemas estaduais de avaliação: uso dos resultados, implicações e tendências. Cadernos de Pesquisa, São Paulo, v. 40, n. 141, p. 793-822, set./dez. 2010.

Notas

${ }^{1}$ Freitas (2007), Sousa e Oliveira (2010), Nardi e Schneider (2012), Alves e Soares (2013) são alguns exemplos.

${ }^{2}$ Pesquisa realizada com apoio do Programa Observatório da Educação (Obeduc), da Coordenação de Aperfeiçoamento de Pessoal de Nível Superior - CAPES/Brasil.

${ }^{3}$ Com o processo de transição do ensino fundamental de oito para nove anos, determinado em 2006, as redes vêm implantando progressivamente o novo regime de duração. Considerando esse processo, as escolas amostradas, por ocasião do levantamento dos dados, ainda possuíam turmas de $4^{\text {a }}$ e $8^{\mathrm{a}}$ séries, motivo pelo qual optamos por adotar essa designação na análise dos dados.

${ }^{4}$ Para o cálculo do Ideb da 5a série o tempo T é obtido com base no fluxo escolar dos alunos até esta série, no ano de aferição do índice. Já para o cálculo do Ideb da 9a série, o tempo T é obtido com base no fluxo da

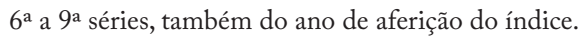

${ }^{5}$ Para o cálculo do Ideb das regiões e dos estados são levados em conta os resultados da Aneb-Saeb, constituídos por avaliações amostrais a estudantes de $5^{\mathrm{a}}$ e $9^{\mathrm{a}}$ séries do ensino fundamental e $3^{\mathrm{a}}$ série do ensino médio, de escolas públicas e privadas.

* Professor Doutor da Universidade do Oeste de Santa Catarina, Xanxerê, Santa Catarina - Brasil.

** Professora Doutora da Universidade do Oeste de Santa Catarina, Xanxerê, Santa Catarina - Brasil. 


\section{Correspondência}

Elton Luiz Nardi - Universidade do Oeste de Santa Catarina, Área de Ciências Humanas e Sociais. Rua Getúlio Vargas, 2125, Jardim Flor da Serra, CEP: 89600-000 - Joacaba, Santa Catarina - Brasil.

E-mail: elton.nardi@unoesc.edu.br - marilda.schneider@unoesc.edu.br

Recebido em 10 de junho de 2013

Aprovado em 12 de novembro de 2013 
